\title{
BMJ open Differences in risk factors for voluntary early retirement and disability pension: a 15-year follow-up in a cohort of nurses' aides
}

\author{
Lone Donbæk Jensen, ${ }^{1}$ Pia Køhler Ryom, ${ }^{2}$ Michael Victor Christensen, ${ }^{1}$ \\ Johan Hviid Andersen ${ }^{3}$
}

To cite: Jensen LD,

Ryom PK, Christensen MV, et al. Differences in risk factors for voluntary early retirement and disability pension: a 15year follow-up in a cohort of nurses' aides. BMJ Open 2012;2:e000991.

doi:10.1136/bmjopen-2012000991

- Prepublication history and additional material for this paper are available online. To view these files please visit the journal online (http://dx.doi.org/10.1136/ bmjopen-2012-000991)

Received 7 February 2012 Accepted 26 September 2012

This final article is available for use under the terms of the Creative Commons Attribution Non-Commercial 2.0 Licence; see http://bmjopen.bmj.com

\footnotetext{
${ }^{1}$ Department of Occupational Medicine, Danish Ramazzini Centre, Aarhus University Hospital, Denmark ${ }^{2}$ Department of Occupational Medicine, Danish Ramazzini Centre, Aalborg University Hospital, Denmark

${ }^{3}$ Department of Occupational Medicine, Danish Ramazzini Centre, Herning University Hospital, Denmark
}

\section{ABSTRACT}

Objective: To estimate the extent of early retirement and to examine risk factors for voluntary early retirement and disability pension in a cohort of nurses' aides.

Design: Register study including baseline questionnaire and register data covering all transfer incomes from 1991 to 2008 in a cohort of nurses' aides established in 1993 with a follow-up period of 15 years.

Setting: Nurses' aides working in nursery homes, homecare or hospitals.

Participants: 3332 gainfully employed nurses' aides at the time of inclusion in the study.

Outcome: Disability pension or early voluntary retirement.

Results: $16.2 \%$ of the population was granted disability pension and $27.1 \%$ entered early voluntary retirement in the follow-up period representing 11186 lost working years with a direct cost in transfer payment amounting about $€ 410$ million. Health-related risk factors for disability pension was long-lasting lowback pain (HR 2.27(95\% Cl 1.55 to 3.34), sick leave because of upper-extremity disorders (HR 2.18 (95\% $\mathrm{Cl} 1.08$ to 2.11), and inflammatory rheumatic disease (HR $2.42(95 \% \mathrm{Cl} 1.67$ to 3.52)). Of non-health-related factors, low education, workers compensation case, evening work and high-rated perceived exertion at work all were minor risk factors for disability pension. The primary risk factor for early voluntary retirement was low education (HR 3.19 (95\% Cl 2.65 to 3.85$)$ ).

Conclusions: $43.3 \%$ of nurses' aides gainfully employed in 1993 retired before due time during the follow-up period. Work-related factors at baseline only seemed to have a minor prognostic role. Risk factors for disability pension were mainly health-related factors, whereas economical factors seemed to influence the decision to choose early voluntary retirement. The number of persons and the amount of lost working years underscores the need of a more active counselling towards maintaining employment especially among those with persistent musculoskeletal disorders.

\section{ARTICLE SUMMARY}

Article focus

- High prevalences of low back pain and sick leave are found among healthcare workers in many countries.

- Predictors of negative vocational prognosis for healthcare workers are unknown.

Key messages

- Musculoskeletal complaints at baseline predicted disability pension but not voluntary early retirement. Work-related factors played a minor role as risk factors for both disability pension and voluntary early retirement.

- For both outcomes, we found no associations with smoking, low physical leisure activity or body mass index.

- Our results point at secondary prevention managing especially musculoskeletal claims at an early state in preventing disability pension.

Strength and limitations of this study

- Study strengths are a follow-up time of 15 years in a national register with a high accuracy and completeness and the possibility to compare risk factors for two different types of early retirement. Study limitations are that data on prognostic factors were self-reported and assessed at one point only.

\section{INTRODUCTION}

Ten per cent of the European workforce is occupied in the healthcare sector. ${ }^{1}$ Several, mainly cross-sectional studies have reported adverse health effects among healthcare workers especially nurses' aides and homecare workers. Most of the studies comprise low back pain (LBP) $)^{2-5}$ and other musculoskeletal disorders. ${ }^{6}$ Also risks of affective and stress-related disorders ${ }^{7}$ and hand eczema ${ }^{9}$ have been discussed.

High prevalence of sick leave is found among nurses, nurses' aides and homecare workers in many countries. ${ }^{10}{ }^{11}$ There are 
only few studies of predictors of early retirement among healthcare workers ${ }^{12}$ or leaving nursing care. ${ }^{13}$ Disability pension is reported to be associated with increased mortality $^{14}$ and with better health ${ }^{15}$ dependent on socioeconomically class. ${ }^{1617}$

Lack of nursing personnel are thought to be a serious problem in many countries in the future due to ageing of the actual workforce and population, a rapid job turnover and problems with recruitment. ${ }^{1}{ }^{13}$ To face these problems, there is a need of studies of predictors of early retirement in the profession to be able to strengthen the prevention of negative vocational outcomes being of benefit for both the nursing personnel and the society.

\section{Objectives}

To estimate the extent of early retirement and examine and compare predictors established at baseline from a self-reported questionnaire including data of demographic, health and work conditions and socioeconomical history from register data of two different types of early retirement: voluntary early retirement and disability pension in a cohort of occupational employed nurses' aides in a follow-up period of 15 years.

\section{METHODS}

A prospective register study of predictors of early retirement in a fixed cohort including all nurses' aides registered in 1992 in the county of Aarhus with 15 years of follow-up.

\section{Study population and data sources}

The cohort was identified by data from an insurance fund (Danish acronym PENSAM) including all former and current persons registered as nurses' aides for minimum 1 year in 1992 in the county of Aarhus. 74\% of the cohort $(n=4616)$ completed a questionnaire including demographic, lifestyle, physical and psychological workload and disease-related factors in $1993 .{ }^{3}$ The part of this population gainfully employed as a nurse's aides, $\mathrm{n}=3332$ in 1993, comprised the study cohort for the present study. The Danish civil personal registration number (CPR) was used to link questionnaire data with person-specific data from the Danish National Register on Public Transfer Payments (Danish acronym DREAM) ${ }^{18}$ from 1991 to 2008 (both years inclusive). Data of permanent transfer income were available from the start of the register in 1991 while information on non-permanent transfer payments as sick leave and unemployment benefit is available from 1997. The follow-up data included data from the DREAM register with weekly registration of public transfer payment at individual level in the follow-up period. We recorded the original 104 different transfer-payment codes from the DREAM register into five variables: (1) employment, (2) sick leave, (3) unemployment benefit, (4) other non-permanent transfer payment as vocational rehabilitation and social assistance, disability pension and flex job a health-dependent halftime pension and (6) voluntary early retirement. The register is thought to be near-to-complete based on the economical incentive for the employer to report to public authorities. The cohort was followed in the DREAM register until 2008 providing a follow-up time of 15 years.

\section{Assessment of main outcome}

The main outcome was permanent early retirement in the follow-up period as disability pension or early voluntary retirement. Lost working years were calculated by extracting the person age at the year of early retirement from 65 which is the year of old-age pension in Denmark. Obtaining disability pension require an evaluation of work ability which is to be reduced to a minimum whereas early voluntary retirement are independent of health status. Voluntary early retirement is available from the age of 60 years if the persons have achieved 25 years of membership of an unemployment benefit fund for a period of 30 years. For each patient, disability pension and voluntary early retirement was estimated, including time and the person's age at the time of achievement of early retirement. Disability pension includes flex job, which was introduced in the year 2000 as a healthdependent half-time pension achieved in the same legislation context as disability pension, based on a permanent health-dependent condition. According to the rules of achievement of early voluntary retirement, it is not possible to change from disability pension to early voluntary retirement. If a person has changed from early voluntary retirement to disability pension, she is classified with the outcome disability pension $(n=8)$. The register gives no information of reason for achieving early retirement.

\section{Sample characteristics}

Baseline data were obtained from a self-administered questionnaire completed in 1993. Demographic and background variables included register-based age at January 1993, gender, education divided in education up to 9 years primary school, 10 years primary school or basic vocational course or secondary school, vocational status of spouse dichotomised in paid work or transfer income, marital status.

Live-in with partner (yes or no) and workers compensation case dichotomised into yes or no. A positive answer includes both ongoing and confirmed cases. Physical work factors were assessed by questions of: working hours per day, evening or night, working place hospital or eldercare, index describing heaviness of care where heavy care was defined by a combination of having more than $2 / 3$ of the daily patients needing full care together with more than 10 handlings of persons per day. Rated perceived exertion (RPE) was assessed from a modified Borg scale range $0-14^{19}$ anchored $1=$ very very light and $13=$ very very strenuous, values $\geq 8$ was defined as high RPE. 
Psychosocial work factors were assessed using a Danish version $^{20}$ of Karasek's Job Content Questionnaire which is shown to have acceptable internal consistency in the healthcare sector. ${ }^{21}$ The three items in the demand score were time pressure, perceived strain and tiredness returning from work. The range in the demand index score was 5-15, low demand were defined by values lower or equal to 9 . The three items in the decision latitude score were possibilities of decision of work pace, how the work was carried out and work disposition. The range in the decision latitude index score was 5-15. High decision latitude was defined by values lower or equal than 9. Violence at work assessed by five items: never, seldom, sometimes, often and very often. Upper-extremity and lower-extremity symptoms was assessed using Nordic questionnaire, ${ }^{22}$ and serious upper-extremity complaints was defined as sick leave $>30$ days for at least one region within the last year; serious lower-extremity complaints was defined as sick leave $>30$ days for at least one region within the last year. LBP was assessed by pain drawing including the level of radiating pain combined with $0-10$ points visual analogue scale, describing the level of usual pain and duration of pain, was assessed by a question asking: 'For how long have you altogether had low-back pain the last year, with the response alternatives 0 days, 1-7 days, 830 days, 31-90 days, more than 90 days?' and a question asking 'Have you ever had acute LBP in relation to person handling or other work tasks?' Knowledge of health parameters as lung diseases, nervous system diseases, skin diseases, cardiovascular disease, gastro intestinal diseases and rheumatological inflammatory diseases was obtained from a list of questions in the questionnaire 'Have our physician ever told you that you have one or more of the following diseases?' Lung disease included asthma, chronic bronchitis and pneumonia, nervous system diseases, skin disease included eczema and cardiovascular disease included elevated blood pressure, angina pectoris, unsteady hearth, coronary infarction and arteriosclerosis. Gastrointestinal diseases included colon irritable and duodenal ulcers, and rheumatological inflammatory included rheumatoid arthritis and inflammatory connective tissue disease. Lifestyle variables comprised body mass index (BMI) dichotomised $\geq 30$ =high versus $\mathrm{BMI}<30$, actual smoking yes/no, physical activity eight items dichotomised: moderate physical activity more than three times a week or more versus less or no activity. For the part of the population achieving early retirement after 1998, pattern and cumulated sick leave in the 2 year period before early retirement were estimated from register data.

\section{Statistical analysis}

After linking data from the PENSAM register including all nurses' aides in the geographical area of interest and the DREAM register by CPR numbers, the vocational record in the 15 years follow-up for each person was established. Relevant covariates were tested for colinearity which was not found. We used Cox proportional hazards models to examine the longitudinal association between the outcome measure and the full set of predictor variables. The HR of achieving disability pension or early voluntary pension was estimated with $95 \%$ CI. The analyses were made separately for disability pension and voluntary early retirement where the reference group for both groups was part of the population receiving neither disability pension nor voluntary early retirement. SAS V.9.1.3 (SAS Institute Cary, North Carolina, USA) and STATA 11.0 were used to perform data management and statistical analyses.

\section{RESULTS}

\section{Study population}

The invited population in 1993 comprised all nurses' aides $(n=6231)$ in the county of Aarhus with at least 1 year seniority as nurses' aides work in the preceding 5 year representing about 200 different working sites. The response rate in 1993 was $74 \%$. Table 1 shows a register-based non-response analysis.

Table 1 Non-response analyses, including all nurses' aides in the county of Aarhus 1993 with more than 1 year of nursing aides work during the last 5 years, $n=6231$

\begin{tabular}{lll}
\hline Register data DREAM & $\begin{array}{l}\text { Questionnaire respondents } 1993 \\
\mathrm{n}=\mathbf{4 6 1 6}\end{array}$ & $\begin{array}{l}\text { Questionnaire non-respondents 1993 } \\
\mathbf{n}=1615\end{array}$ \\
\hline Age 1.7.1993 mean (SD) & $42.7(9.4)$ & $44.3(11.0)$ \\
Years working as nurses' aides 1 July & $10.9(7.1)$ & $11.2(7.4)$ \\
1993 mean (SD) & 98.1 & 97.1 \\
Gender woman (\%) & 2.3 & 3.4 \\
Ethnicity other than Danish (\%) & 2.5 & 3.0 \\
Dead in the follow-up period (\%) & 16.2 & 14.8 \\
Granted disability pension in the follow-up & & \\
period (\%) & 18.2 & \\
Voluntary early retirement in the follow-up & & \\
period (\%) & & \\
DREAM, Danish National Register on Public Transfer Payments.
\end{tabular}


There were only minor differences between the responders and the non-responders concerning the two outcome measures and population characteristics.

The response rate among people with foreign ethnicity was lower than the non-foreign group, probably because of language problems. In the questionnaire response, 3332 participants stated that they were working as nurses' aides at the time they completed the questionnaire. Those 3332 comprised the study population in the present paper.

The baseline characteristics of the 3332 respondents are shown in table 2. The population is mainly female with a mean age of 41.9 years, $70 \%$ with education below secondary school and experienced in nursing care with a mean of 13 years seniority. In all, $69.5 \%$ was working in homecare or at nursery homes and $30.5 \%$ in hospitals in accordance with figurers for Denmark as a whole at that time. ${ }^{23}$ The prevalence of having more than 90 days of back pain was $13.6 \%$; $44.4 \%$ scored their rated perceived exertion more than or equal to 8 (strenuous), 48.7\% experienced high job demands and 24.1\% low decision latitude according to the Karasek model. A minor part, $5.9 \%$, reported violence at work often or very often, and $15.9 \%$ was physical active with at least once in a week with strenuous physical activity.

\section{Early retirement and lost working years}

As seen from the flow chart figure 1, 540 persons $(16.2 \%)$ were granted disability pension and 904 persons $(27.1 \%)$ obtained voluntary early retirement, altogether $43.3 \%$ in the follow-up period.

The total number of lost working years in the population presuming that all persons who retired early had remained at work until the normal pension age is 7472 years for the 540 persons who were granted disability pension and 3714 years for the 904 persons obtaining early retirement, altogether 11186 years amounting about $€ 410$ million in direct costs from early retirement transfer payments.

Figure 2 shows an increasing number of participants who chose early voluntary retirement during the follow-up period, whereas the number per year being granted disability pension is stable until 2002 with a rise in the following years until 2007, where a decline is seen. At that time, there is a corresponding rise in voluntary early retirement. This pattern could be explained by a change in the interpretation of the disability pension legislation. The mean age of those granted disability pension is stable between 50 and 55 years over the 15 -year follow-up period. The minimum age obtaining early voluntary pension is 60 years. The drop below 60 years in 1995 is explained by a temporary change in the legislation. Altogether, 344 persons chose to postpone early voluntary retirement after having got their early voluntary pension certificate: 55 to the age of 61 year, 166 to the age of 62,12 to the age of 65 and 6 to the age of 66 year.
Figure 3 includes distribution of work, sick leave, unemployment benefit and other non-permanent transfer incomes every week in the 2 years preceding the granting of disability pension, respectively, early voluntary retirement. The population is restricted to persons changing to early retirement from 1999 as we only have data on sick leave from 1997 in the DREAM register.

Figure 3 reveals that disability pension is preceded by a decline in work presence from about $60 \% 2$ years prior to the week of disability pension to about $20 \%$ 12 weeks before. During the 2 years preceding disability pension, there is an increase in other transfer incomes with a lower benefit probably because sick leave by Danish legislation is restricted to 52 weeks. The Danish legislation offers the person a possibility to be sick listed as unemployed which can explain the decline in number receiving unemployment benefit.

As seen in figure 3, the pattern of vocational status in the 2 years preceding the time of early retirement differs completely between disability pension and voluntary early retirement. Contrasting the transfer income pattern seen in the 2 years proceeding the time of disability pension, there is no change in the part of the population working or receiving non-permanent transfer income 2 years before starting early voluntary retirement. A bigger proportion compared to the part of the population who are granted disability pension is receiving unemployment benefit with an increasing number over the 2 years.

\section{Risk factors for early retirement}

Table 3 shows adjusted risk factors of being granted disability pension or choosing early voluntary retirement in the follow-up period.

Health-related risk factors for disability pension was more than 90 days of LBP during the last 12 years (HR 2.27 (95\% CI 1.55 to 3.34$)$ ), more than 30 days of sick leave because of upper-extremity disorders (HR 2.18 (95\% CI 1.08 to 2.11 )), more than 30 days of sick leave because of lower extremity disorders (HR 1.51 (95\% CI 1.08 to 2.11)), inflammatory rheumatic disease (HR 2.42 (95\% CI 1.67 to 3.52)) and gastrointestinal disorders (HR 1.39 (CI 1.10 to 1.76)). Of non-health factors, low education (HR 1.27 (95\% CI 1.02 to 1.57$)$ ), workers' compensation case (HR 1.51 (95\% CI 1.23 to 1.87)), evening work (HR 1.29 (95\% CI 1.03 to 1.60)) and highrated perceived exertion at work (HR 1.23 (95\% CI 1.00 1.51)) were independent risk factors. Risk factors for early voluntary retirement were low education (HR 3.19 (95\% CI 2.65 to 3.85), high job demands (HR 1.28 (95\% CI 1.09 to 1.50$)$ ), inflammatory rheumatic disease (HR 1.76 (95\% CI 1.25 to 2.48)), cardio vascular disease (HR 1.47 (95\% CI 1.27 to 1.69)) and gastrointestinal disorders (HR 1.39(95\% CI 1.10 to 1.76)).

Apart from low education, gastrointestinal disorders and inflammatory rheumatic diseases, the two types of early retirement do not share any prognostic factors for the two types of early retirement. Lifestyle factors as 
Table 2 Baseline characteristics among the study population of nurses' aides working in hospital or nursery home/homecare at the time of baseline registration

\begin{tabular}{|c|c|c|c|c|}
\hline Baseline characteristics & $\begin{array}{l}\text { Study } \\
\text { population } \\
\mathrm{n}=3332\end{array}$ & $\begin{array}{l}\text { No early retirement in the } \\
\text { follow-up period } \\
n=1888\end{array}$ & $\begin{array}{l}\text { Voluntary early pension in } \\
\text { the follow-up period } \\
n=904\end{array}$ & $\begin{array}{l}\text { Disability pension in the } \\
\text { follow-up period } \\
n=540\end{array}$ \\
\hline Age, mean(SD) & $41.9(8.2)$ & $37.3(5.4)$ & $51.3(5.1)$ & $42.4(6.8)$ \\
\hline Age obtaining early retirement mean (SD) & & & $60.7(1.9)^{\star}$ & $50.7(6.0)$ \\
\hline \multicolumn{5}{|l|}{ Gender (\%) } \\
\hline Men & 1.7 & 1.9 & 1.5 & 1.3 \\
\hline Women & 98.3 & 98.1 & 98.5 & 98.7 \\
\hline \multicolumn{5}{|l|}{ Education/grade \% } \\
\hline Basic vocational course & 41.6 & 41.3 & 46.4 & 35.0 \\
\hline Secondary school & 29.1 & 35.8 & 17.3 & 25.6 \\
\hline \multicolumn{5}{|l|}{ Vocational status spouse (\%) } \\
\hline Paid work & 73.2 & 79.2 & 63.6 & 67.8 \\
\hline Transfer income & 26.8 & 20.8 & 36.4 & 32.8 \\
\hline \multicolumn{5}{|l|}{ Marital status (\%) } \\
\hline \multicolumn{5}{|l|}{$\begin{array}{l}\text { Married/live in partner } \\
\text { Workers' compensation }\end{array}$} \\
\hline \multicolumn{5}{|l|}{ Work hours (\%) } \\
\hline Mainly day work & 43.4 & 44.0 & 44.0 & 40.2 \\
\hline Mainly evening work & 24.8 & 24.4 & 23.7 & 28.5 \\
\hline Mainly night work & 10.5 & 9.8 & 11.4 & 11.7 \\
\hline Mixed & 21.3 & 21.9 & 20.9 & 19.6 \\
\hline \multicolumn{5}{|l|}{ Heaviness of care duties } \\
\hline indext (\%) high & 11.0 & 11.4 & 9.3 & 12.6 \\
\hline \multicolumn{5}{|l|}{ RPE $\ddagger$ (range 0-14)(\%) } \\
\hline high $\geq 8$ & 44.4 & 43.5 & 41.6 & 53.3 \\
\hline \multicolumn{5}{|l|}{ Violence at work (\%) } \\
\hline Never & 42.8 & 38.8 & 45.2 & 44.8 \\
\hline Seldom & 23.8 & 25.3 & 24.0 & 21.3 \\
\hline On and of & 27.6 & 29.9 & 25.3 & 27.2 \\
\hline Often & 4.3 & 4.4 & 4.4 & 4.4 \\
\hline Very often & 1.6 & 1.7 & 1.1 & 2.2 \\
\hline
\end{tabular}




\begin{tabular}{|c|c|c|c|c|}
\hline Baseline characteristics & $\begin{array}{l}\text { Study } \\
\text { population } \\
\mathrm{n}=3332\end{array}$ & $\begin{array}{l}\text { No early retirement in the } \\
\text { follow-up period } \\
n=1888\end{array}$ & $\begin{array}{l}\text { Voluntary early pension in } \\
\text { the follow-up period } \\
n=904\end{array}$ & $\begin{array}{l}\text { Disability pension in the } \\
\text { follow-up period } \\
n=540\end{array}$ \\
\hline 1-7 days & 25.4 & 27.8 & 23.0 & 21.9 \\
\hline 8-30 days & 20.3 & 22.3 & 17.5 & 18.0 \\
\hline $31-90$ days & 7.8 & 9.0 & 5.5 & 7.4 \\
\hline More than 90 days & 13.6 & 9.1 & 14.0 & 28.3 \\
\hline \multicolumn{5}{|l|}{ Usual back pain (\%) } \\
\hline Radiation below knee level & 15.9 & 13.6 & 15.1 & 25.4 \\
\hline $\begin{array}{l}\text { Ever acute LBP in relation to patient handling or other work } \\
\text { tasks (\%) }\end{array}$ & 58.8 & 57.2 & 56.1 & 69.3 \\
\hline $\begin{array}{l}\text { More than } 30 \text { days of sick leave the last year because of } \\
\text { upper limb disorder (\%) }\end{array}$ & 4.2 & 1.9 & 4.5 & 11.7 \\
\hline $\begin{array}{l}\text { More than } 30 \text { days of sick leave the last year because of } \\
\text { lower limb disorder (\%) }\end{array}$ & 4.7 & 2.5 & 5.2 & 11.9 \\
\hline Cardiovascular disease (\%) & 14.5 & 10.9 & 20.5 & 17.2 \\
\hline Lung diseases $(\%)$ & 23.2 & 22.8 & 21.1 & 28.2 \\
\hline Skin diseases(\%) & 16.7 & 18.2 & 11.7 & 19.4 \\
\hline Gastro intestinal diseases (\%) & 12.6 & 10.0 & 14.9 & 18.2 \\
\hline Rheumatologic inflammatory diseases (\%) & 2.8 & 1.3 & 4.0 & 6.1 \\
\hline Nervous disorder (\%) & 4.1 & 3.1 & 4.4 & 7.6 \\
\hline Current smoking, (\%) & 47.0 & 47.4 & 41.9 & 54.4 \\
\hline BMI, mean(SD) & $23.4(3.8)$ & $23.0(3.5)$ & $24.0(3.5)$ & $23.9(5.0)$ \\
\hline \multicolumn{5}{|l|}{$\mathrm{BMI}$} \\
\hline severe overweight $>30$ & 5.1 & 4.7 & 5.9 & 5.7 \\
\hline Physical activity§ High (\%) & 15.3 & 17.5 & 11.7 & 12.8 \\
\hline
\end{tabular}

LBP, low back pain; BMI, body mass index.

*60 years is the lower limit for voluntary early retirement.

tIndex based on part of clients needing full care in combination with number of person handlings a day.

¥Rated perceived exertion 0-14 scale, anchored $1=$ very very light and $13=$ very very strenuous.

§Physical activity high: at least one time a week strenuous physical activity. ${ }^{24}$ 
Figure 1 Flow chart, selection and course of study population.
1992

1993

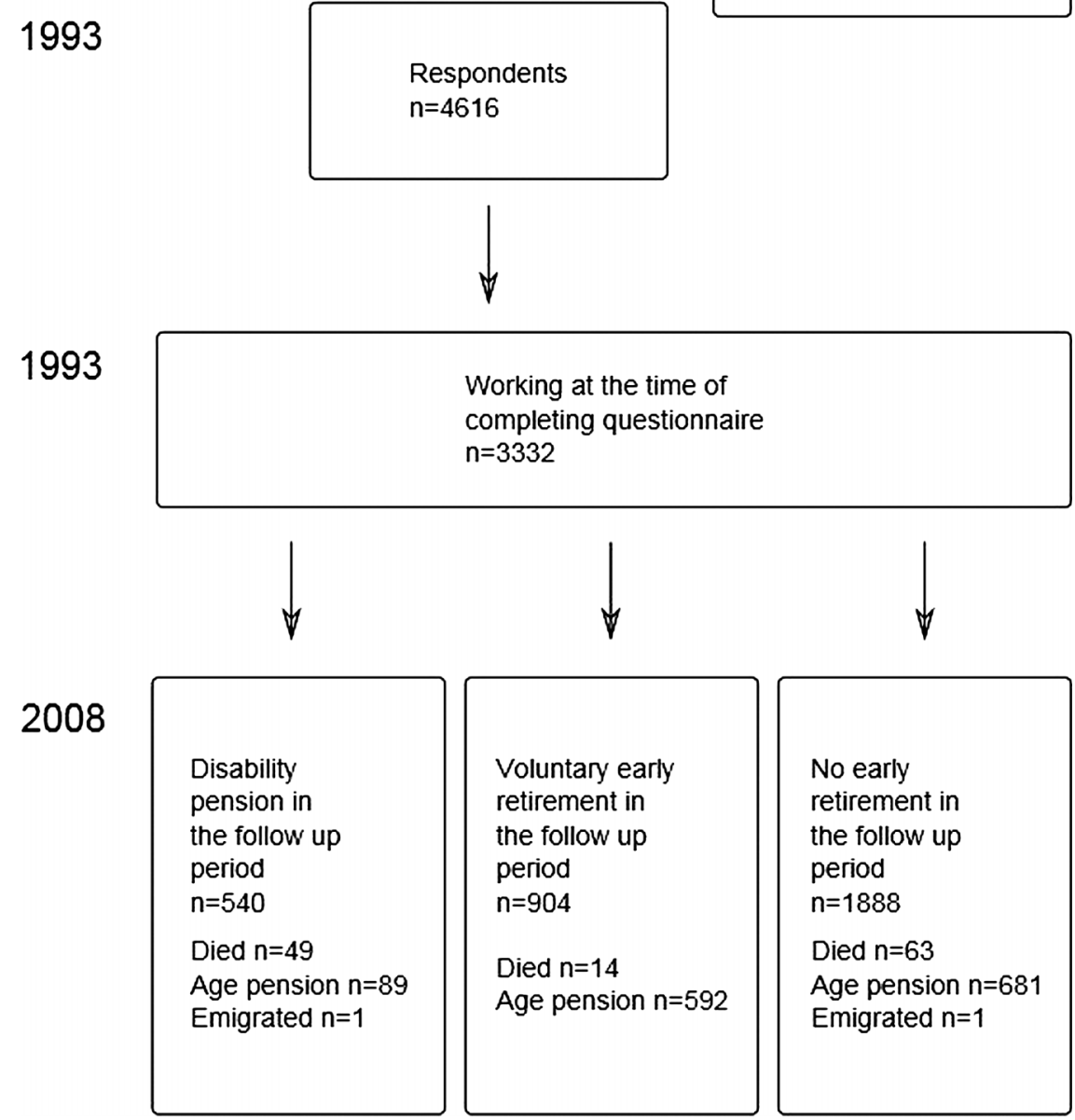

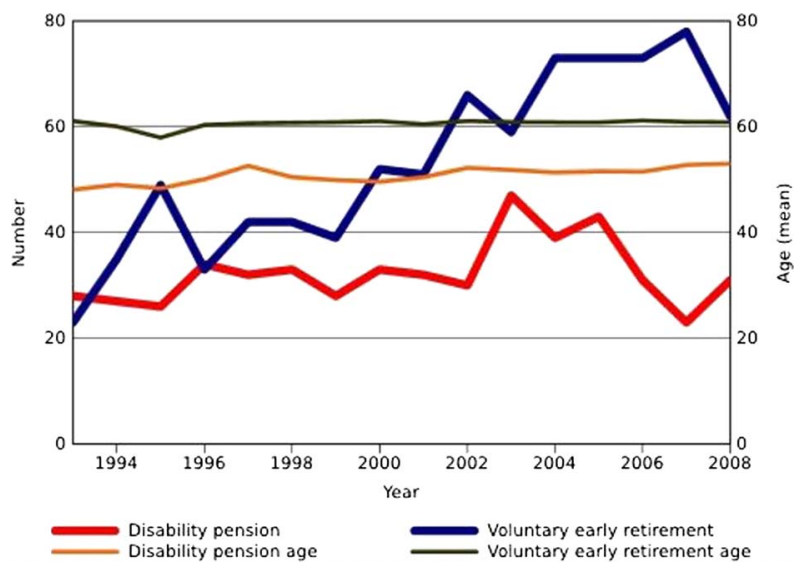

Figure 2 Time trends in number and mean age of persons obtaining early retirement from 1993-2008.

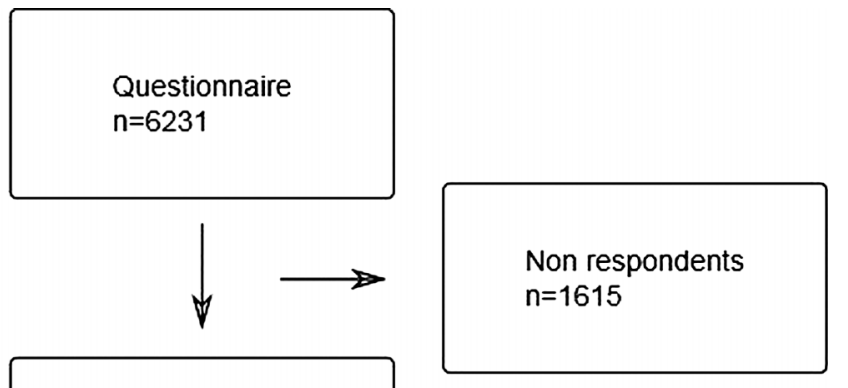

BMI, smoking and physical activity did not show associations with either of the two outcomes. Living alone protected against voluntary retirement, but showed up as a risk factor for disability pension.

\section{DISCUSSION}

This study compared risk factors for two different types of early retirement and thereby contribute to the discussion on the disability process and how to prevent disability and social exclusion. ${ }^{15} 2526$ The study documents a high number of early retirement in a cohort with an earlier strong connection to the labour market with an enormous number of lost productive years and money in direct costs from disability pension and voluntary early retirement. Risk factors for disability pension were mainly health-related factors in accordance with the fact that health-related reduction of the working capacity is 
Disability pension $(n=367)$

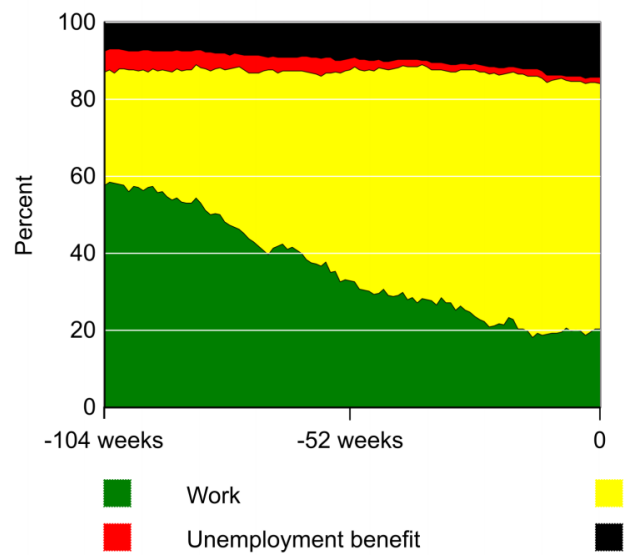

Early voluntary retirement $(n=665)$

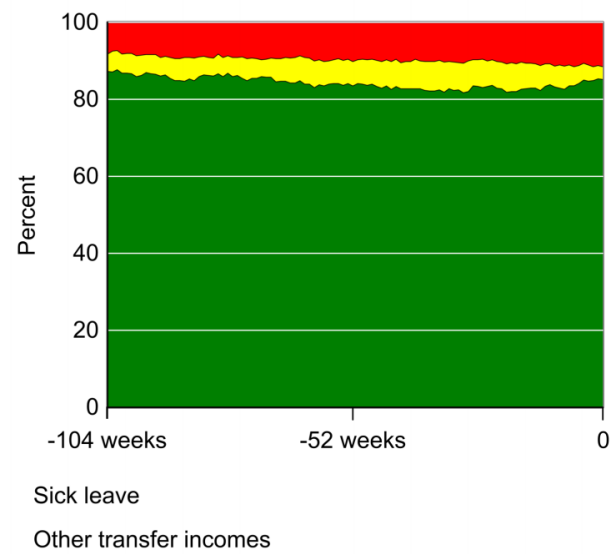

Figure 3 Vocational status, sick leave and other transfer incomes 104 weeks before start of disability pension or voluntary early retirement the period 1999-2008. Zero on the x-axis indicates the week the person started getting disability pension or early voluntary retirement.

the most important criteria for granting disability pension. HR above 2 for disability pension were LBP more than 90 days during the last year, more than 30 sick leaves last year and known rheumatological inflammatory disease at baseline registration in 1993. A worker's compensation case was an independent risk factor, which has been found in other studies. ${ }^{27} 28$ This finding could result from residual confounding as it is possible that the persons notified for a worker's compensation case have more serious health problems than the persons not notified. In this study, the introduction in the model of interaction variables between compensation status and pain variables decreased the HR, and is in favour of more serious health problems among compensation cases. Another explanation could stem from accelerating a disability process by which the compensation system works and impacts on the worker, and we cannot exclude that this could play a role. This study could not corroborate that physical or psychosocial workload found in other studies ${ }^{12} 26$ 29-31 played a major role as targets for primary prevention. Rated perceived exertion at work, but not the heaviness of clients assessed from an index based on number of clients needing full care in combination with number of person handlings a day, was a risk factor. The finding of an elevated risk of evening work are in accordance with a Danish register study focusing on shift work in all sectors and disability ${ }^{32}$ and the only work-related factor with an elevated risk of choosing early voluntary retirement was high demands at work. The interaction term job strain did not contribute to the models (results not shown). In a study from the Finnish public service sector, ${ }^{26}$ it is argued that job strain are to be evaluated on job unit level; in this study, we have information of 200 different work sites. But as the nursery homes, home care units or hospitals in the actual study are rather different in size, we do not have the possibility to make valid work site-aggregated measures of exposure.
Many studies report associations between sick leave and disability pension. ${ }^{33}$ To our knowledge, no other studies have investigated risk factors of early voluntary retirement. Early voluntary retirement at the age of 60 years was mainly associated with low educational level, and the protective effect of spouse being on income transfer and living alone is consistent with primarily economic imperatives for choosing early voluntary retirement. In this study, we found no strong argument for health-related factors as being important in the decision to retire voluntary, except for small effects from cardiovascular, rheumatological inflammatory diseases and gastrointestinal disease.

For both outcomes, we found no associations with smoking, low physical leisure activity or BMI, and this finding questions the ongoing activity at the work site for making individual lifestyle factors the main suspects for intervention in order to stay active in work for more years. ${ }^{34}$

The finding that voluntary early retirement and disability pension only has few mutual prognostic factors, challenges common notions of a retirement process driven by work-related or health-related factors.

The pattern of vocational status in the 2 years preceding the time of early retirement differs completely between disability pension and voluntary early retirement.

Different legislation obviously play a role but it is although surprising that health-related and work-related factors seem to be without importance for people choosing voluntary early retirement in a profession which in many investigations are found to be physical and psychological demanding. ${ }^{2-5}$

A major strength in the present study is the prospective design and number of observations of the two outcomes of early retirement.

In this study, early retirement—both disability pension and voluntary retirement-was assessed from a national register, including weekly registration of all types of 
Table 3 HR of obtaining voluntary early pension or disability pension in the study period according to baseline information

\begin{tabular}{|c|c|c|c|c|}
\hline \multirow{2}{*}{ Risk factors } & \multicolumn{2}{|c|}{$\begin{array}{l}\text { Voluntary early } \\
\text { pension } n=904\end{array}$} & \multicolumn{2}{|c|}{$\begin{array}{l}\text { Disability pension } \\
\mathrm{n}=540\end{array}$} \\
\hline & HR & $95(\%) \mathrm{Cl}$ & HR & $95(\%) \mathrm{Cl}$ \\
\hline \multicolumn{5}{|l|}{ Education grade } \\
\hline Secondary school & 1 & & 1 & \\
\hline 10 years primary school or & 0.83 & 0.65 to 1.06 & 0.92 & 0.71 to 1.18 \\
\hline \multicolumn{5}{|l|}{ Basic vocational course } \\
\hline 7-9 years primary school & 3.19 & 2.65 to 3.85 & 1.27 & 1.02 to 1.57 \\
\hline \multicolumn{5}{|l|}{ Vocational status spouse } \\
\hline Transfer income versus paid work & 0.55 & 0.46 to 0.67 & 1.11 & 0.85 to 1.45 \\
\hline \multicolumn{5}{|l|}{ Marital status } \\
\hline Living alone versus live in partner & 0.64 & 0.51 to 0.80 & 1.54 & 1.14 to 2.09 \\
\hline \multicolumn{5}{|l|}{ Workers compensation } \\
\hline Case & 1.02 & 0.84 to 1.23 & 1.51 & 1.23 to 1.87 \\
\hline \multicolumn{5}{|l|}{ Workplace } \\
\hline nursery home/homecare versus Hospital & 1.04 & 0.88 to 1.23 & 1.08 & 0.87 to 1.35 \\
\hline \multicolumn{5}{|l|}{ Work hours } \\
\hline Mainly day work & 1 & & 1 & \\
\hline mainly evening work & 1.03 & 0.86 to 1.23 & 1.29 & 1.03 to 1.60 \\
\hline Mainly night work & 1.16 & 0.92 to 1.46 & 1.18 & 0.87 to 1.61 \\
\hline Mixed & 0.90 & 0.74 to 1.11 & 0.97 & 0.74 to 1.27 \\
\hline \multicolumn{5}{|l|}{ Heaviness of care duties } \\
\hline Index* high & 0.79 & 0.62 to 1.01 & 0.98 & $0.74-1.29$ \\
\hline \multicolumn{5}{|l|}{ RPE† (range 0-14) } \\
\hline high $\geq 8$ & 0.96 & 0.82 to 1.13 & 1.23 & 1.00 to 1.51 \\
\hline Decision latitude -low & 1.09 & 0.92 to 1.28 & 0.90 & 0.72 to 1.12 \\
\hline Demand -high (\%) & 1.28 & 1.09 to 1.50 & 0.92 & 0.75 to 1.13 \\
\hline \multicolumn{5}{|l|}{ Number of days LBP the last 12 month altogether } \\
\hline 0 days & 0.98 & 0.77 to 1.24 & 1.36 & 0.93 to 1.26 \\
\hline 1-7 days & 0.71 & 0.56 to 0.89 & 1.34 & 0.94 to 1.92 \\
\hline $8-30$ days & 0.71 & 0.55 to 0.91 & 1.35 & 0.92 to 1.97 \\
\hline 31-90 days & 0.58 & 0.40 to 0.82 & 1.29 & 0.81 to 2.05 \\
\hline More than 90 days & 0.72 & 0.54 to 0.97 & 2.27 & 1.55 to 3.34 \\
\hline Usual back pain: radiation below knee level & 0.90 & 0.73 to 1.10 & 1.18 & 0.05 to 1.48 \\
\hline Ever acute LBP in relation to patient handling or other work tasks & 1.07 & 0.89 to 1.27 & 1.01 & 0.80 to 1.28 \\
\hline More than 30 days of sick leave the last year because of upper limb disorder & 1.04 & 0.72 to 1.50 & 2.18 & 1.57 to 3.01 \\
\hline More than 30 days of sick leave the last year because of lower limb disorder & 0.91 & 0.63 to 1.31 & 1.51 & 1.08 to 2.11 \\
\hline Cardiovascular disease & 1.47 & 1.27 to 1.69 & 1.14 & 0.94 to 1.38 \\
\hline Lung diseases & 0.88 & 0.75 to 1.05 & 1.14 & 0.93 to 1.39 \\
\hline Skin diseases & 0.61 & 0.49 to 0.75 & 1.13 & 0.90 to 1.42 \\
\hline Gastro intestinal diseases & 1.21 & 1.00 to 1.47 & 1.39 & 1.10 to 1.76 \\
\hline Rheumatologic inflammatory diseases & 1.76 & 1.25 to 2.48 & 2.42 & 1.67 to 3.52 \\
\hline Nervous disorder & 0.87 & 0.62 to 1.24 & 1.31 & 0.92 to 1.87 \\
\hline Current smoking & 0.80 & 0.69 to 0.93 & 1.20 & 0.98 to 1.45 \\
\hline \multicolumn{5}{|l|}{ BMI } \\
\hline Severe overweight > 30 & 0.87 & 0.64 to 1.17 & 0.85 & 0.57 to 1.26 \\
\hline Physical activity $\ddagger$ low & 0.87 & 0.74 to 1.02 & 0.94 & 0.77 to 1.15 \\
\hline
\end{tabular}

transfer income from the social system. The registers are time-accurate and complete concerning disability pension and early voluntary retirement because it is a part of the payment system. Another strength of this study was the opportunity to look at a population early retired without a legislative requirement of disability.
Exploring risk factors for disability pension in a uniform population have the advantages that the results are less dependent on residual confounding as underlying socioeconomical factors which are known to be strong predictors of disability. ${ }^{35}$ The data on prognostic factors was self-reported and assessed at one point only. 
The information about the non-musculoskeletal symptoms was limited to a question, 'Have our physician ever told you that you have one or more of the following diseases?' The register gives no information of the diagnose behind the disability pension. Knowledge of the specific health-related reasons for the disability pension could have given the opportunity to estimate predictors for different reasons for obtaining disability pension.

The lacking information of sick leave before 2007 rules out the inclusion of sick-leave data in the prognostic model for both outcomes. The study has a high external validity concerning the Danish health and eldercare as the study population comprises a total population of nurses' aides in a well-defined geographical area representative for the rest of Denmark including a loss to follow-up analyses which support the representativeness of the study population. As membership of a pension fund and trade union is mandatory, the original register of nurses' aides are thought to be near to complete. We assume that the working conditions as perceived exertion in care duties, part of very care needing client's use of helping equipment in the eldercare in 1993 are comparable with working conditions during the follow-up period. There had been a tendency towards heavier clients and lesser time per client but, on the other hand, a growing use of helping devices. Our assumption is supported by description of working conditions in studies from 2003, 2004 and 2005. ${ }^{11} 36$ As to generalisability to other countries, both differences in legislation across countries and differences in standard of equipment and working procedures are to be taken into account.

\section{CONCLUSION}

In conclusion, we find an alarming high proportion of early retirement from an area of growing importance for society in the years to come. The lack of shared risk factors for the two types of early retirement was unexpected in a population sharing social and working characteristics, but also points to the importance of being aware of underlying legislation when translating data partly driven on legislation. Work-related factors at baseline in 1993 only seemed to play a minor prognostic role for early retirement of both kinds, and individual factors as smoking, BMI and physical activity at baseline were not associated with early retirement at all. Risk factors for disability pension were mainly health-related factors, whereas economical factors such as income of spouse and unemployment, seemed to influence the decision to choose early voluntary retirement.

Our results point at secondary prevention managing especially musculoskeletal claims at an early state in preventing disability pension with the aim to stay occupied despite musculoskeletal symptoms.

\section{POLICY IMPLICATIONS}

The huge number of lost working years in a population with an initially strong connection to the labour market calls for action, where the finding that musculoskeletal symptoms up to 15 years before disability pension are prognostic factors points at a more active counselling and help to restore connection to the labour market among those with musculoskeletal problems.

Contributor LDJ, PKR and JHA designed the study and made the analyses. MVC performed the data management. All the authors approved the final manuscript.

Funding The Danish insurance fund PENSAM.

Competing interests None.

Patient consent Obtained.

Ethics approval The study has been notified to and authorised by the Danish Data Protection Agency J.nr. 2007-41-0667.and notified to the local ethic and scientific committee J.nr. 1992-1110-892.

Provenance and peer review Not commissioned; externally peer reviewed.

Data sharing statement No additional data are available.

\section{REFERENCES}

1. Fallentin N, Faber A, Sharipova M. Fysiske belastninger $i$ plejearbejdet. Resultater fra en spørgeskemaundersøgelse i den kommunale ældrepleje. Copenhagen: Det nationale forskningscenter for arbejdsmiljø; 2007:1-26, NFA-Rapport SOSU-Rapport 14.

2. Eriksen W, Bruusgaard D, Knardahl S. Work factors as predictors of intense or disabling low back pain; a prospective study of nurses' aides. Occup Environ Med 2004;61:398-404.

3. Jensen LD, Andersen JH, Ryom P. Kroniske lænderygsmerter hos sygehjælpere-en undersøgelse af forekomst og risikofaktorer. Copenhagen: Arbejdsmiljøfondet, 1995:3-90.

4. Lagerstrom M, Hansson T, Hagberg M. Work-related low-back problems in nursing. Scand J Work Environ Health 1998;24:449-64.

5. Ngan K, Drebit S, Siow S, et al. Risks and causes of musculoskeletal injuries among health care workers. Occup Med (Lond) 2010;60:389-94.

6. Eriksen W. The prevalence of musculoskeletal pain in Norwegian nurses' aides. Int Arch Occup Environ Health 2003;76:625-30.

7. Hannerz H, Tuchsen F. Hospitalizations among female home-helpers in Denmark, 1981-1997. Am J Ind Med 2002;41:1-10.

8. Wieclaw J, Agerbo E, Mortensen PB, et al. Occupational risk of affective and stress-related disorders in the Danish workforce. Scand $J$ Work Environ Health 2005;31:343-51.

9. Dulon M, Kromark K, Skudlik C, et al. Prevalence of skin and back diseases in geriatric care nurses. Int Arch Occup Environ Health 2008;81:983-92.

10. Bourbonnais $\mathrm{R}$, Mondor M. Job strain and sickness absence among nurses in the province of Quebec. Am J Ind Med 2001;39:194-202.

11. Horneij EL, Jensen IB, Holmstrom EB, et al. Sick leave among home-care personnel: a longitudinal study of risk factors. BMC Musculoskelet Disord 2004;5:38.

12. Dellve L, Lagerstrom M, Hagberg M. Work-system risk factors for permanent work disability among home-care workers: a case-control study. Int Arch Occup Environ Health 2003;76:216-24.

13. Fochsen $\mathrm{G}$, Josephson $\mathrm{M}$, Hagberg $\mathrm{M}$, et al. Predictors of leaving nursing care: a longitudinal study among Swedish nursing personnel. Occup Environ Med 2006;63:198-201.

14. Wallman $\mathrm{T}$, Wedel $\mathrm{H}$, Johansson $\mathrm{S}$, et al. The prognosis for individuals on disability retirement. An 18-year mortality follow-up study of 6887 men and women sampled from the general population. BMC Public Health 2006;6:103.

15. Westerlund $\mathrm{H}$, Vahtera J, Ferrie JE, et al. Effect of retirement on major chronic conditions and fatigue: French GAZEL occupational cohort study. BMJ 2010;341:c6149.

16. Mein $G$, Martikainen $P$, Hemingway $H$, et al. Is retirement good or bad for mental and physical health functioning? Whitehall II longitudinal study of civil servants. J Epidemiol Community Health 2003;57:46-9.

17. Brockmann H, Müller R, Helmert U. Time to retire-time to die? A prospective cohort study of the effects of early retirement on long-term survival. Soc Sci Med 2009;69:160-4.

18. Hjollund NH, Larsen FB, Andersen JH. Register-based follow-up of social benefits and other transfer payments: accuracy and degree of 
completeness in a Danish interdepartmental administrative database compared with a population-based survey. Scand J Public Health 2007;35:497-502.

19. Josephson M, Hagberg M, Hjelm EW. Self-reported physical exertion in geriatric care. A risk indicator for low back symptoms? Spine (Phila Pa 1976) 1996;21:2781-5

20. Nord-Larsen M, Ørhede E, Nielsen J, et al. Lønmodtagernes arbejdsmiljø 1990. Copenhagen: Arbejdsmiljøfondet, 1992.

21. Sale JE, Kerr MS. The psychometric properties of Karasek's demand and control scales within a single sector: data from a large teaching hospital. Int Arch Occup Environ Health 2002;75:145-52.

22. Kuorinka I, Jonsson B, Kilbom A, et al. Standardised Nordic questionnaires for the analysis of musculoskeletal symptoms. Appl Ergon 1987;18:233-7.

23. Amstrup G, Andersen A. Rapport fra arbejdsgruppen vedrørende analyse af behovet for plejepersonale. Copenhagen: Sundhedsministeriet og Amtsrådsforeningen i Danmark, 1994.

24. Hagberg M. Frageformular som anvants $i$ Stockholm-MUSIC I av Stockholm MUSIC I Study Group. Solna: MUSIC-Books, 1990.

25. Black DC. Working for a healthier tomorrow. Dame Carol Black's review of the health of Britain's working population. Presented to the secretary of state for health and the secretary of state for work and pensions 17th March 2008. London: TSO, 2008.

26. Laine S, Gimeno D, Virtanen M, et al. Job strain as a predictor of disability pension: the Finnish public sector study. J Epidemiol Community Health 2009;63:24-30.

27. Atlas SJ, Chang Y, Keller RB, et al. The impact of disability compensation on long-term treatment outcomes of patients with sciatica due to a lumbar disc herniation. Spine (Phila Pa 1976) 2006;31:3061-9.
28. Iles RA, Davidson M, Taylor NF. Psychosocial predictors of failure to return to work in non-chronic non-specific low back pain: a systematic review. Occup Environ Med 2008;65:507-17.

29. Ahola K, Virtanen M, Honkonen T, et al. Common mental disorders and subsequent work disability: a population-based Health 2000 Study. J Affect Disord 2011;134:365-72.

30. Hannerz H, Tuchsen F, Spangenberg S, et al. Industrial differences in disability retirement rates in Denmark, 1996-2000. Int J Occup Med Environ Health 2004;17:465-71.

31. Vahtera J, Laine S, Virtanen M, et al. Employee control over working times and risk of cause-specific disability pension: the Finnish Public Sector Study. Occup Environ Med 2010;67:479-85.

32. Tuchsen F, Christensen KB, Lund T, et al. A 15-year prospective study of shift work and disability pension. Occup Environ Med 2008;65:283-5.

33. Gjesdal S, Bratberg E, Maeland JG. Musculoskeletal impairments in the Norwegian working population: the prognostic role of diagnoses and socioeconomic status: a prospective study of sickness absence and transition to disability pension. Spine (Phila Pa 1976) 2009;34:1519-25.

34. Lydell M, Baigi A, Marklund B, et al. Predictive factors for work capacity in patients with musculoskeletal disorders. J Rehabil Med 2005;37:281-5.

35. Haukenes I, Mykletun A, Knudsen AK, et al. Disability pension by occupational class - the impact of work-related factors: the Hordaland Health Study Cohort. BMC Public Health $2011 ; 11: 406$.

36. Jensen LD, Gonge $\mathrm{H}$, Jors $\mathrm{E}$, et al. Prevention of low back pain in female eldercare workers: randomized controlled work site trial. Spine (Phila Pa 1976) 2006;31:1761-9. 